\title{
Efficacy of Low-cost Intraoral Prosthesis in the Era of Modern Radiation Therapy in Oral Cancer Patients
}

\author{
Shivani Sharad Desai ${ }^{1}$, Adnan Calcuttawala $^{2}$, Dipti Patil ${ }^{3}$, Nilesh Deshmane $^{4}$, Sharad Desai $^{5}$
}

\begin{abstract}
Aim and objective: To fabricate a customized intraoral prosthesis (IOP) and determine its dosimetric, clinical, and economic impact in oral cancer patients undergoing radiation therapy (RT).

Materials and methods: Intraoral prosthesis was made using routine chairside and laboratory techniques using alginate, dental stone, and heat cure acrylic resin. Modifications in the IOP were made according to the specific case. Six patients with head and neck cancers (HNC) involving either of the jaws, planned to receive either adjuvant or definitive RT with the presence of one or more risk factors of developing severe acute radiation-induced toxicities were enrolled in this study.

Results: With the use of a customized IOP during radiation treatment, an improvement in radiation-induced oral mucositis (RIOM) was observed from grade III to grade I. There was a significant reduction in the radiation dose received by normally involved structures of the oral cavity. The minimal cost of the fabrication of IOP negates the cost involved in the management of severe grade RIOM and its complications.

Conclusion: Fabrication of a low-cost customized IOP in oral cancer patients undergoing RT is feasible and its use with modern techniques of RT planning and delivery can reduce the doses to the normal tissues in the oral cavity, thereby reducing the severity of RIOM in patients with cancers of the oral cavity.

Clinical significance: Radiation therapy has significant acute side effects like mucositis, oral ulceration, and impaired taste, which increases morbidity leading to multiple breaks in the treatment. Also, the negative psychological impact of these side effects causes them to discontinue the treatment, thus worsening the disease outcome. We present a study on the fabrication of a custom-made, and affordable IOP and its efficacy in decreasing the severity of acute side effects of RT.

Keywords: Intraoral prosthesis, Oral cancer, Radiation therapy, Radiation-induced oral mucositis.

World Journal of Dentistry (2021): 10.5005/jp-journals-10015-1880
\end{abstract}

\section{INTRODUCTION}

Oral cancer is the sixth most common cancer in the world and ranked third in the Indian subcontinent. It is most commonly seen in the low socioeconomic strata because of the tobacco chewing and smoking habits with a trend toward higher incidence in the younger age group. Lack of awareness regarding oral health, inadequate access to trained healthcare providers, and the cost are significant factors for delay in the diagnosis which consequently affects the treatment outcome. $^{1-3}$ In oral cancer, surgery is the primary treatment modality, which is usually followed by radiation therapy (RT) with or without concurrent chemotherapy to improve cancer-related outcomes in locally advanced cancers. ${ }^{2}$ Radiation therapy is associated with acute and late side effects. The common acute side effects include oral mucositis, ulceration, and impaired taste sensation. Late effects include xerostomia, dental caries, and osteoradionecrosis. ${ }^{4,5}$

The use of intraoral prosthesis (IOP) has been shown to reduce the incidence and severity of radiation-induced side effects either by shielding or displacing the uninvolved structures. It also ensures stability and reproducibility during daily radiation treatment. ${ }^{4,6}$

Being an essential part of the multidisciplinary team of head and neck oncology, the dentist provides complete oral evaluation and treatment along with custom-made prostheses to the patients to prevent radiation-induced complications.

We are presenting an original article to evaluate the efficacy of a customized IOP in oral cancer patients undergoing RT under the following objectives:

- To fabricate a customized IOP for a selected group of oral cancer patients undergoing RT. $\overline{{ }^{1-5} \text { Department of Dentistry, Shiv Cancer Institute, Miraj, Maharashtra, }}$ India

Corresponding Author: Shivani Sharad Desai, Department of Dentistry, Shiv Cancer Institute, Miraj, Maharashtra, India, Phone: +14694286361, e-mail: shivani.desai007@gmail.com

How to cite this article: Desai SS, Calcuttawala A, Patil D, et al. Efficacy of Low-cost Intraoral Prosthesis in the Era of Modern Radiation Therapy in Oral Cancer Patients. World J Dent 2021;12(6):463-468.

Source of support: Nil

Conflict of interest: None

- To determine the dosimetric and clinical impact of the use of IOP in this group.

- To determine the economic impact in terms of costs and benefits with the use of IOP.

The need of this study is necessary to prove that low-cost IOP is efficient and helpful for a patient who is undergoing RT. This procedure does not require expensive procedures like CAD/CAM processing neither it uses material like lead or lithium which makes other modes more expensive.

\section{Materials and Methods Selection of Participants}

Six patients from Shiv Cancer Institute, Miraj, were enrolled prospectively after the ethical committee approval for

() The Author(s). 2021 Open Access This article is distributed under the terms of the Creative Commons Attribution 4.0 International License (https://creativecommons. org/licenses/by-nc/4.0/), which permits unrestricted use, distribution, and non-commercial reproduction in any medium, provided you give appropriate credit to the original author(s) and the source, provide a link to the Creative Commons license, and indicate if changes were made. The Creative Commons Public Domain Dedication waiver (http://creativecommons.org/publicdomain/zero/1.0/) applies to the data made available in this article, unless otherwise stated. 
randomized control trial within a period of 5 months from June 1, 2020, to October 31, 2020, satisfying the following inclusion criteria:

- Histologically proven head and neck cancers (HNC) involving either of the jaws, planned to receive either adjuvant or definitive RT.

- Presence of one or more risk factors of developing severe acute radiation-induced toxicities.

Patients were referred to the dental department after evaluation by the radiation oncologist. The dentist reviewed the clinical details of each patient. A complete evaluation of the teeth and surrounding tissues was performed along with any adjuvant dental treatment necessary before the commencement of RT. This commonly included scaling and root planing and extractions of the compromised teeth. Two patients were referred after the development of radiation-induced oral mucositis (RIOM), and the remaining were seen before starting RT. Radiation Therapy Oncology Group (RTOG) grading of mucositis was noted for patients who were referred after the development of RIOM. Mouth opening was assessed, and a customized IOP was fabricated according to the needs of the patient.

\section{Method of Fabrication of IOP}

Alginate impressions of the upper and lower arches were made. The cast was poured into type III dental stone. Bite registration was done using modeling wax. The height of the prosthesis was determined according to the interincisal mouth opening. In the dental lab, the cast was mounted on a hinge articulator. The prosthesis was fabricated using heat cure acrylic material. The patient was recalled the following day and was placed in a supine position with the chin elevated to simulate the RT treatment position. The fabricated
IOP was inserted and adjusted according to the patient's comfort. Stability and ease of insertion were confirmed. The IOP was polished and delivered to the patient.

The patient was then referred back to the RT department, and computed tomography (CT) simulation for RT planning was done with the IOP in situ. Radiation treatment was planned using the volumetric modulated arc therapy (VMAT) technique. Dosimetric analysis of target volumes and organs at risk (OAR) was done using a dose-volume histogram (DVH). The plan was then approved for patient treatment by the radiation oncologist. The patients were kept on weekly review by the RT and dental teams for assessment of RIOM during the course of RT.

\section{Modifications of the IOP According to the Case}

Cases 1 and 2 had dentulous arches hence deviating the adjacent normal structures away from the field of radiation. The IOP was constructed between the premolar and first molar of both arches, which aided in separating the lower jaw and surrounding structures (Fig. 1A).

Cases 3 and 4 had undergone right maxillary surgical resection. The interocclusal IOP was supported by canines and premolars. An additional acrylic extension was added at the lower border to depress the tongue. The tongue depressor extension was modified according to the patient's comfort to relieve him from gagging (Fig. 1B). The position of the IOP intraorally can be observed in (Fig. 1C).

Cases 5 and 6 had undergone mandibular resection. The IOP was constructed to elevate and spare the tongue and separate the maxillary structures (Fig. 2).

Patients were instructed to clean the IOP with soap and water before and after use. They were also instructed to place the IOP in a water-filled container when not in use.
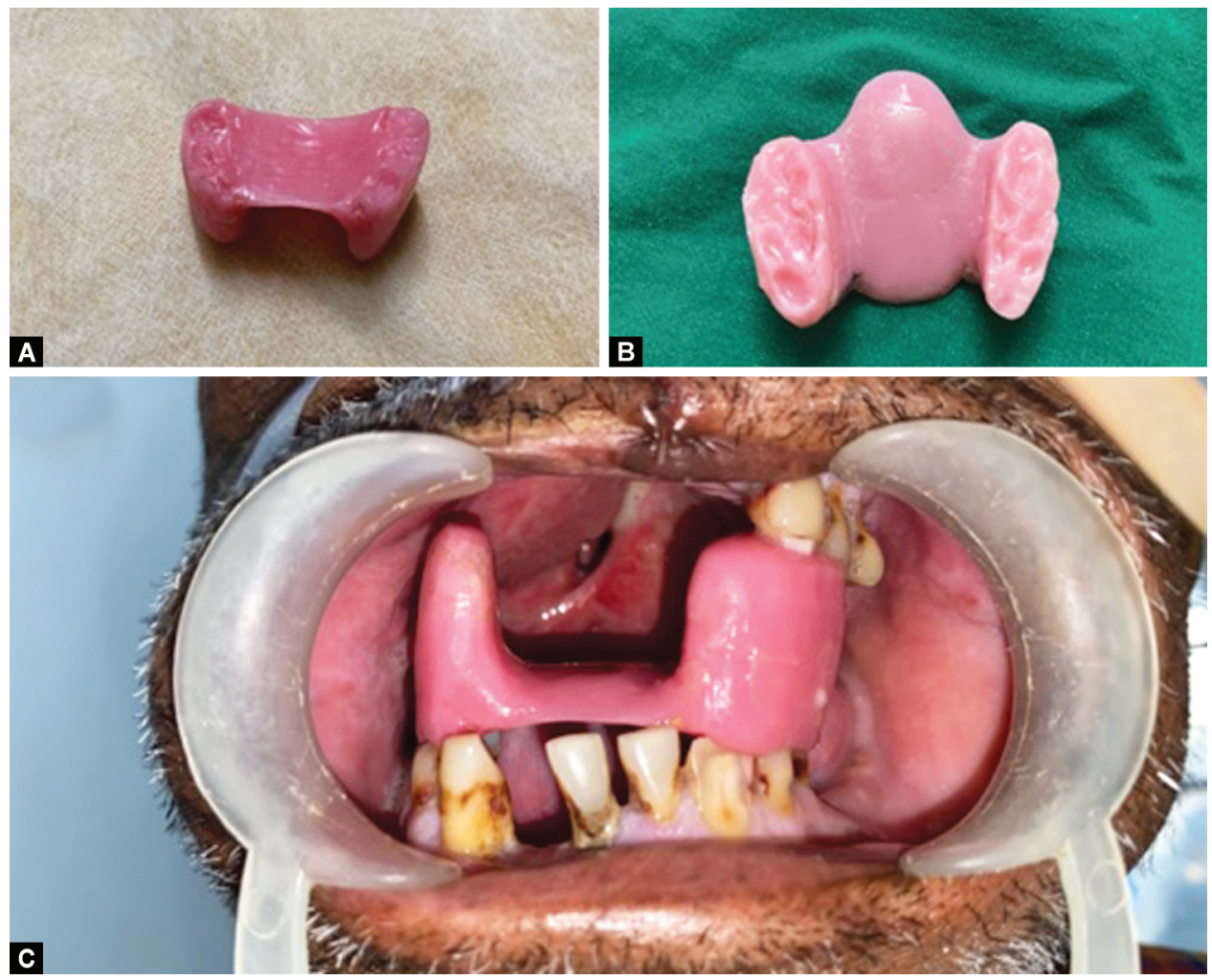

Figs 1 A to C: (A) IOP modified with acrylic extension to depress the tongue; (B) IOP without any modification; (C) IOP placed in intraoral position 


\section{Results}

The demographic and clinical profile of the patients included in the study is listed in Table 1A.

The patients were followed up through their radiation treatment process. An average inter-incisal separation of 29.7 $\mathrm{mm}$ was achieved using the IOP which resulted in a significant separation between the upper and the lower jaws (Fig. 3). Consequently, radiation treatment planning could be done by minimizing the radiation doses to either of the jaws and adjacent oral structures. The dosimetric details of RT plans generated for
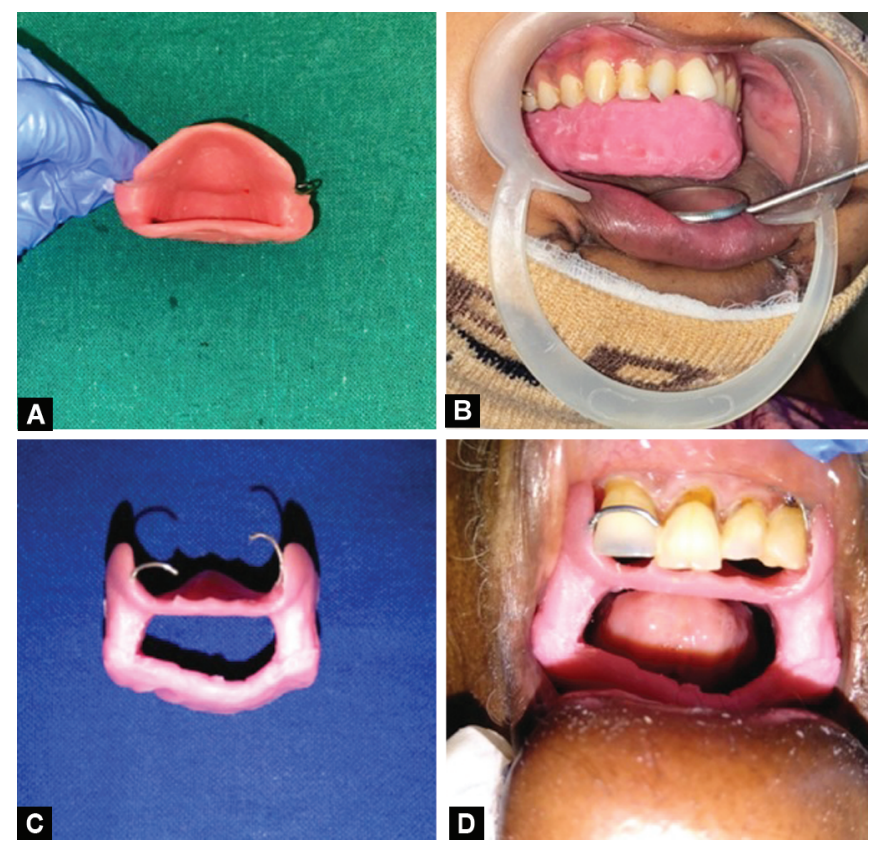

Figs $2 A$ to $D$ : IOP modified to elevate and place the tongue away from the treatment area individual cases using IOP are listed in Table 1B. The average mean dose $\left(D_{\text {mean }}\right) /$ maximum dose $\left(D_{\text {max }}\right) /$ dose received by $40 \%$ volume $\left(D_{40}\right)$ of the lower lip, tongue, and palate were 24.6/46.5/24.7 Gray (Gy), 35.3/60.9/38.6 Gy, and 10.5/22.3/10.6, respectively.

For the first two cases, the doses received by the tongue and lower lip were compared between the plans with and without the use of IOP (Table 1C). It was found that without the use of IOP, the lower lip received an average excess $D_{\text {mean }}, D_{\text {max }}$ and $D_{40}$ of $21.2,28.45$, and $21.25 \mathrm{~Gy}$, respectively, and the tongue received an average excess $D_{\text {mean }}, D_{\text {max }}$ and $D_{40}$ of $18.4 \mathrm{~Gy}, 9.35$ $\mathrm{Gy}$, and $20.6 \mathrm{~Gy}$, respectively. Average $V_{40}$ with IOP for the lower lip was 0 and for the tongue was $24.8 \%$, respectively. The graph represents the difference in the average mean values with and without the use of IOP in the lower lip and tongue of the first two cases.

\section{Note}

- $D_{\text {mean }}$-Mean dosage

- $D_{\max }$-Maximum dosage

- $D_{40}$-Dose received per $40 \%$ volume

- $V_{40}$-Percentage volume receiving $40 \mathrm{~Gy}$

With IOP, it was possible to maintain a constant mouth opening throughout the course of RT, which allowed the jaws to remain separated during treatment delivery. Radiation Therapy Oncology Group grading of RIOM for individual cases is listed in Table 1D. With IOP, a median RTOG grade of I was achieved. For the first two cases wherein RT was initially started without IOP, the RTOG grading of RIOM improved from a median grade of III to a median of grade I after the use of IOP (Fig. 4).

Considering the material cost of alginate used for impression making, dental stone for cast model, modeling wax for bite registration, and laboratory charges, the cumulative expense of the customized IOP approximated to about 2,000-3,000 INR (approximately \$28-\$40) (Table 1E).

Table 1A: Demographic and clinical profile of patients

\begin{tabular}{|c|c|c|c|c|c|c|}
\hline & Case 1 & Case 2 & Case 3 & Case 4 & Case 5 & Case 6 \\
\hline Age & 27 & 70 & 74 & 53 & 35 & 62 \\
\hline Sex & Female & Male & Male & Male & Female & Male \\
\hline Primary site & Left upper alveolus & $\begin{array}{l}\text { Left upper } \\
\text { alveolus }\end{array}$ & $\begin{array}{l}\text { Upper right } \\
\text { alveolus }\end{array}$ & $\begin{array}{l}\text { Right upper } \\
\text { gingivobuccal } \\
\text { sulcus }\end{array}$ & $\begin{array}{l}\text { Lower anterior } \\
\text { alveolus }\end{array}$ & $\begin{array}{l}\text { Lower anterior lip } \\
\text { and alveolus }\end{array}$ \\
\hline TNM stage & $\begin{array}{l}\text { Stage IV-cT4b N2 } \\
\text { M0 }\end{array}$ & $\begin{array}{l}\text { Stage IV-pT4 pNo } \\
\text { M0 }\end{array}$ & $\begin{array}{l}\text { Stage IV-pT4 pNO } \\
\text { M0 }\end{array}$ & $\begin{array}{l}\text { Stage IV-pT4 pNo } \\
\text { M0 }\end{array}$ & $\begin{array}{l}\text { Stage IV-pT4 pNo } \\
\text { M0 }\end{array}$ & $\begin{array}{l}\text { Stage IV-pT4 pNo } \\
\text { M0 }\end{array}$ \\
\hline $\begin{array}{l}\text { Risk factors for } \\
\text { severe RIOM }\end{array}$ & $\begin{array}{l}\text { Concurrent } \\
\text { chemotherapy }\end{array}$ & $\begin{array}{l}\text { Poor oral hygiene, } \\
\text { heavy smoker, } \\
\text { Type } 2 \text { diabetes, } \\
\text { and hypertension }\end{array}$ & $\begin{array}{l}\text { Poor oral hygiene, } \\
\text { smoker }\end{array}$ & Smoker & $\begin{array}{l}\text { Poor oral hygiene, } \\
\text { diabetes mellitus }\end{array}$ & $\begin{array}{l}\text { Chronic tobacco } \\
\text { user }\end{array}$ \\
\hline $\begin{array}{l}\text { Treatment } \\
\text { planned }\end{array}$ & $\begin{array}{l}\text { Definitive } \\
\text { concurrent } \\
\text { chemoradiotherapy }\end{array}$ & $\begin{array}{l}\text { Definitive surgery } \\
\text { followed by } \\
\text { adjuvant radiation } \\
\text { therapy }\end{array}$ & $\begin{array}{l}\text { Definitive surgery } \\
\text { followed by } \\
\text { adjuvant radiation } \\
\text { therapy }\end{array}$ & $\begin{array}{l}\text { Definitive surgery } \\
\text { followed by } \\
\text { adjuvant radiation } \\
\text { therapy }\end{array}$ & $\begin{array}{l}\text { Definitive surgery } \\
\text { followed by } \\
\text { adjuvant radiation } \\
\text { therapy }\end{array}$ & $\begin{array}{l}\text { Definitive surgery } \\
\text { followed by } \\
\text { adjuvant radiation } \\
\text { therapy }\end{array}$ \\
\hline Aim of RT & Definitive & Adjuvant & Adjuvant & Adjuvant & Adjuvant & Adjuvant \\
\hline $\begin{array}{l}\text { Type of prosthe- } \\
\text { sis provided }\end{array}$ & Interocclusal IOP & Interocclusal IOP & $\begin{array}{l}\text { Interocclusal } \\
\text { IOP with tongue } \\
\text { extension }\end{array}$ & $\begin{array}{l}\text { Interocclusal } \\
\text { IOP with tongue } \\
\text { extension }\end{array}$ & $\begin{array}{l}\text { Maxillary plate } \\
\text { with support for } \\
\text { tongue elevation }\end{array}$ & $\begin{array}{l}\text { Maxillary plate } \\
\text { with support for } \\
\text { tongue elevation }\end{array}$ \\
\hline $\begin{array}{l}\text { Inter-incisal jaw } \\
\text { separation }\end{array}$ & $25 \mathrm{~mm}$ & $30 \mathrm{~mm}$ & $30 \mathrm{~mm}$ & $35 \mathrm{~mm}$ & $30 \mathrm{~mm}$ & $28 \mathrm{~mm}$ \\
\hline
\end{tabular}




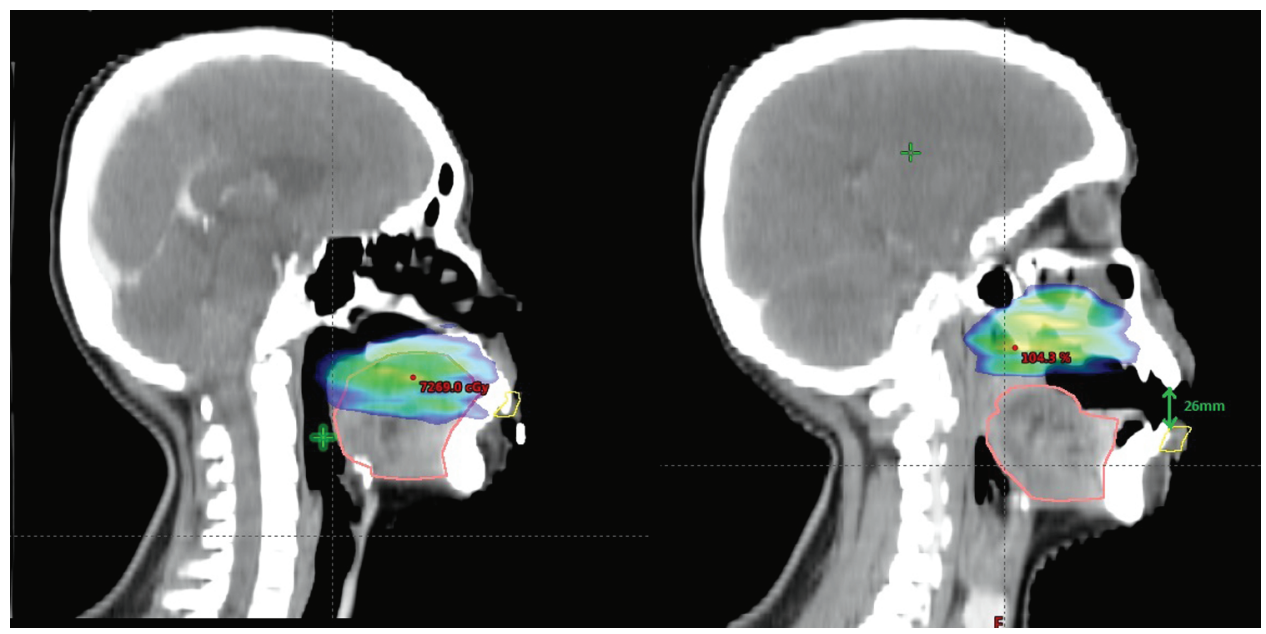

Fig. 3: CT image shows space between the maxillary and mandibular counterparts ( $26 \mathrm{~mm}$ ) and depression of tongue with the use of IOP modified to depress the tongue away from the treatment area

Table 1B: Average mean dose, maximum dose, dose received by $40 \%$ volume of the lower lip, tongue, and palate

\begin{tabular}{|c|c|c|c|c|c|c|c|}
\hline & & Case 1 & Case 2 & Case 3 & Case 4 & Case 5 & Case 6 \\
\hline \multirow[t]{3}{*}{ Lower lip } & $D_{\text {mean }}(\mathrm{Gy})$ & 17.1 & 16.8 & 28.8 & 35.9 & NA & NA \\
\hline & $D_{\max }(\mathrm{Gy})$ & 35.8 & 22.9 & 64.4 & 62.9 & NA & NA \\
\hline & $D_{40}(\mathrm{~Gy})$ & 17.7 & 17.6 & 26.4 & 37 & NA & NA \\
\hline \multirow[t]{3}{*}{ Tongue } & $D_{\text {mean }}(\mathrm{Gy})$ & 33.5 & 32.7 & 40.6 & 36.2 & 37.2 & 31.5 \\
\hline & $D_{\max }(\mathrm{Gy})$ & 65.6 & 52.7 & 61.9 & 62.1 & 62.4 & 60.8 \\
\hline & $D_{40}(\mathrm{~Gy})$ & 36 & 34.4 & 47.6 & 38.1 & 39.4 & 36.1 \\
\hline \multirow[t]{3}{*}{ Palate } & $D_{\text {mean }}(\mathrm{Gy})$ & NA & NA & NA & NA & 17.7 & 3.3 \\
\hline & $D_{\max }(\mathrm{Gy})$ & NA & NA & NA & NA & 39.4 & 5.2 \\
\hline & $D_{40}(\mathrm{~Gy})$ & NA & NA & NA & NA & 17.6 & 3.5 \\
\hline
\end{tabular}

Table 1C: Comparison of radiation dosage, before and after the use of IOP

\begin{tabular}{llllll}
\hline & \multicolumn{3}{c}{ Lower lip } & & \multicolumn{2}{c}{ Tongue } \\
\cline { 2 - 3 } \cline { 5 - 6 } & $\begin{array}{l}\text { Before the } \\
\text { use of IOP }\end{array}$ & $\begin{array}{l}\text { After the } \\
\text { use of IOP }\end{array}$ & & $\begin{array}{l}\text { Before the } \\
\text { use of IOP }\end{array}$ & $\begin{array}{l}\text { After the } \\
\text { use of IOP }\end{array}$ \\
\hline Case 1 & & & & & \\
$D_{\text {mean }}(\mathrm{Gy})$ & 55.5 & 17.1 & 59.2 & 33.5 \\
$D_{\max }(\mathrm{Gy})$ & 72.1 & 35.8 & 72.8 & 65.6 \\
$D_{40}(\mathrm{~Gy})$ & 59 & 17.7 & 66.7 & 36 \\
$V_{40}(\%)$ & 99 & 0 & 97 & 31.6 \\
Case 2 & & & & \\
$D_{\text {mean }}(\mathrm{Gy})$ & 20.7 & 16.8 & 43.7 & 32.7 \\
$D_{\text {max }}(\mathrm{Gy})$ & 42.1 & 22.9 & 63.9 & 52.7 \\
$D_{40}(\mathrm{~Gy})$ & 20.6 & 17.6 & 45.2 & 34.4 \\
$V_{40}(\%)$ & 0.02 & 0 & 52.4 & 18 \\
\hline
\end{tabular}

\section{Discussion}

Surgery and postoperative RT is the most common treatment approach for locally advanced HNC. Large primary tumors, nodal metastasis, invasion into the perineural, lymph, or vascular tissues, portend a high risk of loco-regional recurrence and thus are the primary factors that dictate the use of adjuvant RT. Radiation doses

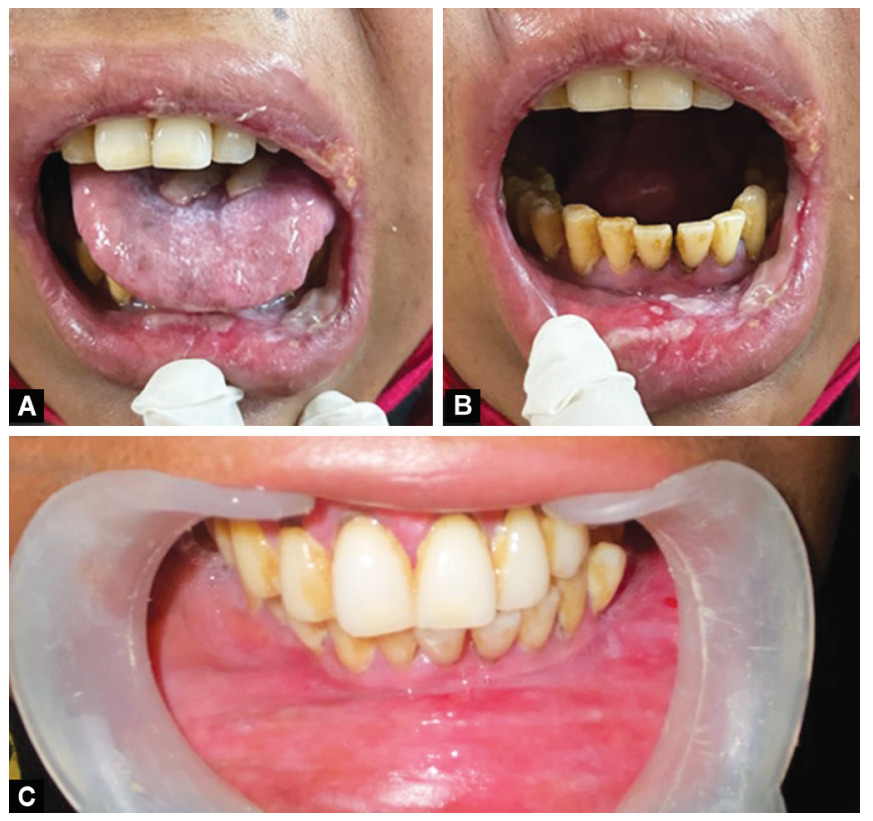

Figs 4A to C: (A) and (B) Grade III RIOM observed on the tongue and lower lip area after receiving radiation of $12 \mathrm{~Gy}$ without the use of IOP; (C) Grade I RIOM observed at the end of the treatment (on receiving 70 Gy) with the use of IOP 
Low-cost Intraoral Prosthesis for Oral Cancer Patients

Table 1D: Mucositis grading (RTOG)

\begin{tabular}{|c|c|c|c|c|c|c|}
\hline & Case 1 & Case 2 & Case 3 & Case 4 & Case 5 & Case 6 \\
\hline $\begin{array}{l}\text { Mucositis grade before the use of } \\
\text { IOP (RTOG) }\end{array}$ & $\begin{array}{l}\text { Grade III (after } 12 \\
\text { Gy of RT) }\end{array}$ & $\begin{array}{l}\text { Grade III (after } 16 \\
\text { Gy of RT) }\end{array}$ & $\mathrm{Nil}^{*}$ & $\mathrm{Nil}^{*}$ & $\mathrm{Nil}^{*}$ & $\mathrm{Nil}^{*}$ \\
\hline $\begin{array}{l}\text { Mucositis grade after the use of } \\
\text { IOP (RTOG) }\end{array}$ & Grade 0 & Grade I & Grade I & Grade 0 & Grade 0 & Grade I \\
\hline
\end{tabular}

Table 1E: RTOG oral mucositis scoring scales ${ }^{7}$

\begin{tabular}{ll}
\hline Grade 0 & None \\
\hline Grade I & Erythema of mucosa \\
Grade II & Patchy reaction $<1.5 \mathrm{~cm}$, non-contiguous \\
Grade III & Confluent reaction $>1.5 \mathrm{~cm}$, contiguous \\
Grade IV & Necrosis or deep ulceration, bleeding \\
\hline
\end{tabular}

can vary, but a total dose of approximately 60 Gy in 30 fractions delivered over 6 weeks, is usually the norm. ${ }^{8,9}$ Radiation-induced oral mucositis is the most common and significant adverse effect that occurs during RT for HNC. ${ }^{3}$

Radiation-induced oral mucositis is a normal tissue injury that starts as an acute inflammation of the oral mucosa, tongue, and pharynx after radiation exposure. Inflammatory cells are recruited, and inflammatory cytokines, chemotactic mediators, and growth factors are released at these sites. Initially, hyperemia and erythema occur during the pre-ulcer phase, with the release of pro-inflammatory cytokines at the site of tissue injury which leads to an epithelial phase of desquamation, basement membrane damage, and loss of the protective barrier, resulting in ulceration. The post-ulcerative phase varies depending on the extent of tissue toxicity. If a secondary infection with gram-negative bacteria or yeast occurs, it causes micro-coagulation of the vasculature, which worsens the inflammation due to local ischemia because of the necrotic tissue. Healing and fibrosis occurs in the final stage. ${ }^{10-12}$

Various factors like old age, female sex, decreased saliva, malnourishment, smoking, increased serum creatinine level, and genetic susceptibility lead to increased risk for oral mucositis. ${ }^{710}$ Use of concurrent chemotherapy and altered radiation fractionation ${ }^{12}$ schedules may also increase the risk of RIOM. ${ }^{11,12}$ In this study, severe RIOM was observed in two patients where risk factors of smoking, concurrent chemotherapy, and chronic microvascular diseases like hypertension and diabetes were identified. Genetic susceptibility was suspected in one of the two patients who gave a history of severe RIOM in a second-degree relative radiated for oral cancer 1 year ago.

Radiation-induced oral mucositis results in decreased intake of food and water leading to malnutrition, weight loss, electrolyte imbalance, and septic complications which may cause an acute lifethreatening situation. It also compromises tumor-related outcomes due to unplanned treatment interruptions. Radiation-induced oral mucositis causes oral pain, dysphagia, an increase in the incidence of feeding tube insertion and hospitalization, and modification or interruption of treatment. ${ }^{7}$ In this study, the patients who had already started RT without the use of IOP, developed grade III mucositis, oral pain, and dysphagia which caused weight loss and unplanned treatment breaks. The patients using prostheses from the beginning of RT developed no such side effects and continued their treatment without any interruption.

Retrospective studies have shown that delay in radiation treatment can worsen cancer-related outcomes. Hence, it is of utmost importance to prevent the overall treatment time delay in patients. ${ }^{11}$ Tarnawski et al. conducted a retrospective study on 1,502 patients with oral cancer who were treated with RT alone. Ninety percent of these patients had unplanned radiation treatment breaks (mean a break of 9 days). They observed that during the radiation treatment break, the clonogens are capable of proliferating three times faster on days when no RT was given than on days when RT was given. $^{12}$

Even with advances in the RT techniques such as IMRT and VMAT, RIOM and its complications remain to be resolved. ${ }^{13}$ Hence, different prosthetic devices have been constructed to displace or shield the tissues adjacent to the target, thereby assisting in the administration of RT to reduce or eliminate the complications. ${ }^{14,15}$ The various radiation devices are constructed using common prosthetic techniques. Prostheses used in RT in the oral and paraoral regions have been classified by Drane and Rahn as locators, carriers, and stents. ${ }^{5}$ Radiation carriers, positioning stents, protecting stents, bolus compensators, and tissue recontouring stents are the different types of radiation stents that can be used. ${ }^{12,16}$

Radiation protection/shielding stent devices either displace or protect the movable vital tissue away from the high-dose regions. Position maintaining stents are used to maintain the position of the structures precisely for multiple radiation treatment fractions. ${ }^{12}$ Tongue depressing stent is a custom-made device used for positioning the tongue during radiation treatment. An interocclusal stent extends lingually from both the alveolar ridges, with a flat plate of acrylic resin that serves to depress the tongue. ${ }^{16,17}$

On conducting a PubMed search of [intraoral stents] AND [radiation induced oral mucositis] only three results were obtained. Only one result was obtained when we searched for [intraoral prostheses] AND [radiation-induced oral mucositis].

In this study, we constructed an IOP to displace the lower jaw and tongue during RT. An IOP with an acrylic extension lingually was made for depressing the tongue away from the target volume. Intraoral prostheses were also modified to elevate and spare the tongue from receiving high doses of radiation in two cases where the lower jaw was the target.

The dosimetric analysis quantifies radiation dose to various structures within the irradiated volume. The DVH is a tool frequently used during IMRT/VMAT to determine the exact radiation dose distribution in the target volume and in any adjacent normal tissues. ${ }^{14,18}$ Verrone et al. observed a decrease in the mean radiation dose to the areas which were not included in the PTV after the use of an intraoral stent. ${ }^{14}$ A retrospective study on 33 patients with cancer of the tongue or floor of mouth showed a decrease in the dose to the contralateral side, including the parotid gland with the use of IOP. ${ }^{18}$ Significant statistical correlation between acute mucositis grade and the $V_{40}$ has been observed. ${ }^{19}$ In this study, we have observed a significant reduction in the radiation dose to the adjacent normal tissue structures. In the two patients where IOP was used after the development of RIOM, we were able to demonstrate a reduction in the doses received by the tongue and the lower lip, 
which translated into a clinical benefit in the form of resolution of the grade III RIOM to grade I RIOM after the use of IOP.

Radiation-induced oral mucositis also has an effect on the cost of care with an increase in the length of hospital stay and higher inpatient costs. Depending on the grade, RIOM is found to be associated with an incremental cost of $\$ 1,700-\$ 6,000$.,20,21 Interruptions during the ongoing RT negatively affects the cancer outcomes, increasing the probability of recurrences in the future. This adds to the overall cost of treatment. It also has a negative impact on the mental health of the patient. In our study, the cost of the IOP was approximately $\$ 28-\$ 40$ which has been shown to reduce the severity of RIOM thus negating the costs involved in the management of severe grade RIOM and the complications arising from it.

This study has been conducted on only six patients which limits any specific inferences derived from the observations made in the study. Dose-volume parameters were assessed to know the success of the prosthesis However, the findings can form a basis for a larger study to determine the effectiveness of the use of customized IOP in reducing $\mathrm{RIOM}$ in the modern era of $\mathrm{RT}$.

\section{Conclusion}

Intraoral prosthesis benefits during radiation treatment by maintaining the airway and immobilization of the oral structures thus aids in reproducibility during the treatment and reduces errors.

Fabrication of a low-cost customized IOP in oral cancer patients undergoing RT is feasible and its use with modern techniques of RT planning and delivery can reduce the doses to the normal tissues in the oral cavity thereby reducing the severity of RIOM in patients with cancers of the oral cavity.

\section{References}

1. Sharma S, Satyanarayana L, Asthana $S$, et al. Oral cancer statistics in India on the basis of first report of 29 population-based cancer registries. J Oral Maxillofac Pathol: JOMFP 2018;22(1):18. DOI: 10.4103/ jomfp.JOMFP_77_20.

2. Day TA, Davis BK, Gillespie MB, et al. Oral cancer treatment. Curr Treatm Opt Oncol 2003;4(1):27-33. DOI: 10.1007/s11864-003-0029-4.

3. Mathur P, Sathishkumar K, Chaturvedi M, et al., ICMR-NCDIR-NCRP Investigator Group Cancer statistics, 2020: report from national cancer registry programme, India. JCO Global Oncology 2020;6(6):1063-1075. DOI: $10.1200 / G O .20 .00122$.

4. Palaskar J, Mody ZS, Mohile SS, et al. Different types of radiation prosthesis to minimise radiation side effects. Int J Curr Res 2016;8:33575-33578.
5. Deng H, Sambrook PJ, Logan RM. The treatment of oral cancer: an overview for dental professionals. Aust Dent J 2011;56(3):244-252. DOI: 10.1111/j.1834-7819.2011.01349.x.

6. Taniguchi H. Radiotherapy prostheses. J Med Dent Sci 2000;47(1):1226.

7. Elting LS, Cooksley CD, Chambers MS, et al. Risk, outcomes, and costs of radiation-induced oral mucositis among patients with head-andneck malignancies. Int J Radiat Oncol Biol Phys 2007;68(4):1110-1120. DOI: 10.1016/j.ijrobp.2007.01.053.

8. Spencer KR, Ferguson JW, Wiesenfeld D. Current concepts in the management of oral squamous cell carcinoma. Aust Dent J 2002;47(4):284-289. DOI: 10.1111/j.1834-7819.2002.tb00539.x.

9. Schiødt M, Hermund N. Management of oral disease prior to radiation therapy. Support Care Cancer 2002;10(1):40-43. DOI: 10.1007/ s005200100284.

10. Verrone JR, Alves FA, Prado JD, et al. Benefits of an intraoral stent in decreasing the irradiation dose to oral healthy tissue: dosimetric and clinical features. Oral Surg, Oral Med, Oral Pathol Oral Radiol 2014;118(5):573-578. DOI: 10.1016/j.00oo.2014.08.008.

11. Ferreira JA, Olasolo JJ, Azinovic I, et al. Effect of radiotherapy delay in overall treatment time on local control and survival in head and neck cancer: review of the literature. Rep Pract Oncol Radiothe 2015;20(5):328-339. DOI: 10.1016/j.rpor.2015.05.010.

12. Maria OM, Eliopoulos N, Muanza T. Radiation-induced oral mucositis. Front Oncol 2017;7:89. DOI: 10.3389/fonc.2017.00089.

13. Mantri SS, Bhasin AS. Preventive prosthodontics for head and neck radiotherapy. J Clin Diagn Res 2010;4:2958-2962.

14. Schaaf NG. Maxillofacial prosthetics and the head and neck cancer patient. Cancer 1984;54(S2):2682-2690. DOI: 10.1002/10970142(19841201)54:2+3.0.co;2-3.

15. Dewan H, Radiation Prosthesis for Improving the Life of Cancer Patients. 2019. DOI: 10.34297/AJBSR.2019.04.000849.

16. Gaba N, Goswami R, Agarwal K. Prosthetic carriers for radiation therapy of head and neck. Adv Biomed Bull 2013;1(2):136-146.

17. Janani T, Suganya R. Clinical demonstration of various radiation stents-an overview. J Pharmaceut Sci Res 2016;8(12):1358.

18. Verrone JR, Alves FA, Prado JD, et al. Impact of intraoral stent on the side effects of radiotherapy for oral cancer. Head Neck 2013;35(7):E213-E217. DOI: 10.1002/hed.23028.

19. Shogan JE, Bhatnagar AK, Heron DE, et al. Dosimetric correlation of oral cavity dose with acute mucositis in patients treated with intensity modulated radiation therapy (IMRT) and chemotherapy. Int J Radiat Oncol Biol Phys 2005;63:S74-S75. DOI: 10.1016/j.ijrobp.2005.07.128.

20. Inoue $Y$, Yamagata $K$, Nakamura $M$, et al. Are intraoral stents effective for reducing the severity of oral mucositis during radiotherapy for maxillary and nasal cavity cancer? J Oral Maxillofac Surg 2020;78(7):1214.e1-1214.e8. DOI: 10.1016/j.joms.2020.02.009.

21. Russo G, Haddad R, Posner M, et al. Radiation treatment breaks and ulcerative mucositis in head and neck cancer. Oncologist 2008;13(8):886-898. DOI: 10.1634/theoncologist.2008-0024. 